\title{
Open Education platforms: Theoretical ideas, digital operations and the figure of the open learner
}

Mathias Decuypere

University of Leuven, Belgium

mathias.decuypere@kuleuven.be

\section{To cite this article:}

Decuypere, M. (2018). Open education platforms: Theoretical ideas, digital operations and the figure of the open learner. European Educational Research Journal, 1-22. DOI: 10.1177/1474904118814141

\section{Available at:}

https://doi.org/10.1177/1474904118814141

\begin{abstract}
Open Education (OE), a generic term for a collection of practices that seek to broaden the access to education through digital means, has gained increasing traction and popularity over the last years and from various corners, both globally and in European circles. Rather than taking the technologies OE makes use of at face value, this article analyzes the concrete operations that Massive Open Online Courses (MOOC) platforms perform, and more specifically the sorts of open learning and the type of open learner that are being shaped by these platforms. Understanding such platforms as active, sociotechnical devices, the article first provides an overview of the conceptual milieu out of which these MOOC platforms originated. In a second part, contemporary MOOC platforms that have concretized out of this milieu are analyzed. Different types of operations that enact a very specific figure of the open learner (and types of open learning) are advanced: The open learner is increasingly being lured and made flexible, controlled and molded, communalized and responsibilized, and finally trained and empowered. The article ends with some outlines for possible future concretizations of OE and its MOOC platforms.
\end{abstract}




\section{Introduction}

Open Education (OE), a generic term for a collection of practices that seek to broaden the access to education through digital means, has gained increasing traction and popularity over the last years and from various corners. Firstly, the concept has attracted attention from international policy organizations such as United Nations Educational, Scientific and Cultural Organization (UNESCO), the Organisation for Economic Co-operation and Development (OECD), and the European Commission. For instance, back in 2013, the European Commission issued the staff working document Opening Up Education, accompanied by the portal openeducationeuropa.eu (a recently discontinued gateway to various European OE initiatives). Furthermore, over the last years the European Commission has funded several external OE platforms such as the EMMA platform (De Rosa et al., 2017).

Secondly, media all over the world have paid substantial attention to one particular aspect of $\mathrm{OE}$ in the form of Massive Open Online Courses (MOOCs). The term "MOOC" was coined by Stephen Downes and George Siemens back in 2008, during the development of a course entitled Connectivism and Connective Knowledge (Downes, 2012). In this course, Downes and Siemens searched for ways to make full use of the affordances of proliferating Web 2.0 technologies, which allowed for the extensive sharing and distribution of content in a networked information environment. Since then, the acronym has been used to refer to a variety of courses that are most of the time massive in scope, open for anyone interested, and delivered on an online basis. Over time, two grand types of MOOCs were characteristically discerned: $\mathrm{CMOOCs}$, which are explicitly based on a (connectivist) learning theory; and the more dominant and well-known XMOOCs, which operate under a more traditional instructional approach (reflecting the traditional university course format of concatenating lectures to a group of students). Many of these XMOOCs are developed by renowned Ivy League universities and disseminated through digital platforms such as Coursera, edX, Udacity, FutureLearn, etc. Even though the MOOC-landscape is characterized by a high diversity that cannot be fully captured by this distinction, c- and XMOOCs have overall received the largest amount of media coverage (Storme et al., 2016). Often touted as disruptive innovations that would radically transform the higher education sector, over the last decade various sorts of MOOCs have been depicted as a technological solution that would fix problems of unequal access and extortionate tuition fees (Dumitrica, 2017).

Lastly, from a scholarly perspective, $\mathrm{OE}$ has equally been framed as a profound transformer of the educational field (e.g., Brown and Adler, 2008; Comeau and Cheng, 2013; Marshall, 2018; Tuomi, 2013). However, scholarship is increasingly making critical comments regarding this transformative potential, and more generally regarding unquestioned assumptions pervading $\mathrm{OE}$ research and $\mathrm{MOOC}$ research. For instance, the often merely rhetorical argument that openness would be an "absolute positive" in and of itself is increasingly being questioned (e.g., Collier and Ross, 2017). Additionally, attention is increasingly being devoted to OE initiatives that cannot be properly captured with the dichotomic $\mathrm{c} / \mathrm{xMOOC}$ divide. For instance, it has been argued that many MOOC platforms are currently overtly transmogrifying from "massive" and "open" into "small" and "private" (Knox, 2017; Watters, 2016). In sum -the emergence of some critical accounts notwithstanding-from a variety of perspectives the $\mathrm{OE}$ field tends to be generally characterized by a lot of enthusiastic yet largely unreflexive rhetoric and hyperbole (Knox, 2013; Weller, 2014; Weller et al., 2018).

Next to such critical remarks about the present state of (dealing with) various sorts of MOOCs, it should equally be noted that $\mathrm{OE}$ is not a completely new phenomenon. It has a broad history; for instance in the form of extension colleges, civil approaches to education, schools of the air, open universities and, more recently, Open Courseware and Open Educational Resources (Baker, 2017; Weller et al., 2018). Thus, despite all rhetoric (as in: "radically new") and technological solutionism (as in: "technologies will solve many contemporary problems") characterizing current MOOC discourse, OE initiatives are in 
essence a continuation and not a disruption of innovation in higher education (Brown, 2016; Krause, 2014; Morozov, 2014; Yuan and Powell, 2013). In addition, critical studies have argued extensively that many MOOC platforms, from their inception onwards, have operated under a neoliberal template, thereby deploying the notions of "openness" and "education" merely as marketing tools (Bayne et al., 2015; Farrow, 2016). In this respect, it has been analyzed that despite their cosmopolitan promises of liberating individuals from social and educational inequalities, many $\mathrm{MOOC}$ initiatives, and notably $\mathrm{xMOOCs}$, tend to reproduce the very socio-economic structures, hierarchies and power relations they (procl)aim to disrupt (Hall, 2015; Schuman, 2013). In sum, critical literature has contextualized OE within, or explained its functioning by referring to, broader historical, economical and/or societal evolutions (e.g., Moe, 2015; Peters and Britez, 2008; Weller, 2014). Approaching OE solely in terms of broader technological progress, neoliberal thought and socio-economic embeddedness, however, does not account for the specific operations that digital platforms perform themselves, such as the shaping of particular types of users and the establishment of specific understandings about learning and education (Emejulu and McGregor, 2016; Knox, 2016; Decuypere, 2016).

In view of these arguments, this article takes a critical orientation toward present (x)MOOC platforms that focuses on the kind of open learner that is claimed to exist and the kind of learning that this learner is expected to undertake. Such a relational understanding of the figure of the open learner is at present largely unreflexively adopted and definitely undertheorized (Knox, 2017; Simons, 2018). Informed by insights from sociomaterial approaches in education (e.g., Edwards and Fenwick, 2015; Gorur, 2013; Gourlay, 2015), this article critically scrutinizes these contemporary platforms not as instrumental hatchways that neutrally convey information, knowledge and/or courses, but instead as active devices that perform particular operations and that, in the process, enact specific ideas about both "open education" and the figure of the "open learner." That is to say, ideas about OE and open learning are articulated materially through the operations of digital MOOC platforms. Whereas previous research has focused on the reproduction of subjectivities according to neoliberal, utilitarian and objectivist ideological templates (see above), the aim of this article is to analyze how such subjectivities are shaped in and through the various operations that MOOC platforms themselves perform. The focus, hence, is neither on contextualizing features that informed the construction and generation of MOOC platforms, nor on the personal experiences of open learners visiting these platforms. Instead, we focus on social and technical operations present on contemporary MOOC platforms, and on how these intervene in shaping specific sorts of open learners and open learning.

\section{A sociomaterial approach to MOOC platforms}

\section{MOOC platforms as socio-technical devices}

This article draws on theoretical and methodological insights from actor-network theory and sociomaterial approaches, and more particularly from the work of Callon, Muniesa and colleagues (Callon and Muniesa, 2005; Muniesa et al., 2007), which enables us to analyze MOOC platforms as socio-technical devices, that is, as active assemblages that act and make their users act.

On the one hand, a focus on technicality allows us to consider digital platforms as devices that possess agency by performing particular operations. The specific sort of (open) education that is being presented on MOOC platforms, hence, is considered as the outcome of operations active in these platforms. Open learners cannot learn just anything and they certainly cannot learn in just any way: What visitors of MOOC platforms can and cannot do is delineated by, and limited to, what these platforms allow them to do (Hartong, 2016). Hence, technical operations render some actions and 
activities possible and others impossible, and in so doing confine and delineate what can and cannot be done when navigating an OE platform (Decuypere et al., 2014).

On the other hand, digital platforms not only act, but equally make their users act: A focus on sociality enables us to disentangle the specific sorts of open learners that are enacted in and through these devices. The analytical focus on sociality, then, amounts to scrutinizing MOOC platforms in view of what they presently enact as being self-evident, necessary, or indispensable kinds of learning and ways of being an open learner (Postma, 2012; Simons, 2015: 1180).

Drawing on these sociomaterial insights, this article contributes to our understanding of the figure of the open learner and the sorts of learning that are currently being enacted through specific operations performed by MOOC platforms. We take the notion of the figure of the open learner in a generic way, and as the sum of the various ways in which the open learner is being shaped today. That is, the figure of the open learner is considered as the result of such shapings. As Muniesa et al. (2007: 3) argue, such shapings do not come out of thin air, but are always dependent on historical processes and circulating ideas. To that effect, and based on an analysis of key theoretical ideas with respect to openness, the article first provides an account of how OE platforms are a specific concretization of a conceptual milieu consisting of various circulating ideas regarding OE (Simondon, 1980). That is to say, socio-technical operations currently performed by digital platforms are always partly dependent on (and situated within) already circulating ideas and trajectories. This implies that contemporary platforms and the operations they perform are to be considered as a set form that is partly originating from previous forms (Serres, 2015). In order to apprehend this set form of operations and ideas, it is important to recognize that platforms not only evolve (i.e., are rendered more concrete) over time, but that equally are shaped by (and at once give shape to) the surroundings in which they are embedded. The distinctiveness of analyzing such concretized forms is that it enables us to discern dominant and established operations and ideas, and equally to describe different forms (Decuypere and Simons, 2016a,b): alternative ways of shaping open learning and the open learner (see Conclusion).

\section{Diagrammatic analysis}

Considered as socio-technical devices, this article presents an analysis of four different (x)MOOC platforms (i.e., edX, Coursera, Udacity, and FutureLearn) in view of their specific performed operations and enacted ideas. In order to do so, we adopt the main tenets of a diagrammatic analysis -a methodological approach that is commonly used in sociomaterial approaches of digital platforms (e.g., Decuypere, 2016, Decuypere and Simons, 2016a; Drucker, 2013; Latour, 1986). Similar to the majority of sociomaterial methods, diagrammatic analyses do not offer stringent guidelines to be followed, but instead seek to install a particular sensibility in the researcher (Fenwick and Edwards, 2010). In diagrammatic analyses, this sensibility is a relational one, which suggests one to focus not only on textual elements, but to equally take visual (photographs, pictures, dashboards, ...) elements into account. The crux of diagrammatic analyses is that they approach both textual and visual elements, and the relational interplay between them, as presentations of a particular sort of (desired or undesired) reality, rather than merely as neutral representations of objective "facts". Additionally, a focus on how the textual and the visual intersect, and thereby generate productive effects, assists in apprehending how underlying code and algorithms work and are operative in practice. To be clear, it is not the intention of this article to analyze such code and algorithms-instead, it is the intention to show how code and algorithms, made operational through text and visuals on educational platforms, act as performative givens, thereby in their turn making their users act in particular ways (Kitchin and Dodge, 2011). 
In order to do so, each platform was regularly visited and relevant sections of the platforms were captured though screenshots and the construction of an (offline) database. Homepages, lesson interfaces and account pages were extensively analyzed with respect to visual and textual elements, and screenshots were taken whenever homepages were updated. Additionally, and as exemplary case studies, we followed one MOOC per platform. Next to that, e-mail messages received (newsletters, promotions, updates, etc.) as registered user of each platform were archived. In this regard, and just like any other sociomaterial analysis, an important issue was where to stop the data collection (where to "cut the network," as Strathern (1996) has it), since the "boundaries" of digital platforms are not easily delineated. For the purposes of this analysis, we pragmatically chose to stay within the confines of each platform, with inclusion of e-mail messages received. This implies that links toward other websites or platforms were not taken into account. Rather than being a limitation of the analysis, this pragmatic delineation allowed for an up-close perspective on the various operations performed within the platform environment themselves (Latour, 2005).

This article starts with a brief account of the (conceptual) milieu from which OE platforms originated. Even though this milieu is characterized by a considerable diversity of ideas, four established ways of thinking about open learning and the open learner will be highlighted: provision, learner control, collaboration, and emancipatory potential. In the sections that follow, we focus on some of the present $\mathrm{xMOOC}$ platforms that have concretized out of this milieu. We more particularly disentangle four sets of socio-technical operations performed by these platforms, and more especially in view of the enactment of very specific types of open learners and open learning. The article ends with some outlines for possible future concretizations of $\mathrm{OE}$ and its $\mathrm{MOOC}$ platforms.

\section{Commonly held ideas about open learning and the open learner}

In order to give an account of the ways of thinking associated with open learning and the open learner, it is important to note that both "openness" and "learning" have historically been associated with a plethora of interpretations and, hence, with considerable conceptual evasiveness (Moe, 2015; Wiley and Green, 2012). Equally at present, "open learning" tends to operate as an empty signifier that can be applied to any digital educational practice in order to give it some sheen of moral authority and transform it into a legitimate and timely form of education (Bayne et al., 2015; Gourlay, 2015). Taking stock of the more reflexive literature (e.g., Peters and Roberts, 2012), however, at least four established ways of thinking about open learning can be discerned.

The first way is the most straightforward, and situates open learning in the ability of learners to freely consume-most of the time digitally provided-learning materials. Open learning is then equated with free learning, and entails the possibility that students consume learning materials at no cost. A consequence hereof is that open learning can be effectuated anywhere and anytime-that is, as long as one has a particular resource at hand. Whereas this focus on free resources has been adopted in ideas about distance and open education, and still is manifestly present in the majority of contemporary $\mathrm{xMOOCs}$, it has often been criticized for not being fully comprehensive in capturing what open learning might entail (Weller, 2014).

Consequently, a second conception of open learning stresses that open learning comprises more than the possibility of simply making use of educational materials at no cost. This perspective is tightly associated with ideas circulating around software developments in the 1990s (Weller, 2014). Free/Libre and Open Source Software (FLOSS) distributions were conceived to be alternatives to (licensed) software distributions that had to be paid for by the user, and that were furthermore limited to their pre-specified usage: Once purchased, the software could be made use of, but neither could it 
be adapted nor distributed further. FLOSS, conversely, allowed the free distribution and adaptation by users, who were allowed to tweak and adapt the software as deemed necessary (albeit to varying degrees-Stallman, 2016). Inspired by this "mixing and mashing" philosophy, open learning has not only been situated in the consumption of learning materials, but equally in the (re)creation of these materials based on a continuous negotiation between teacher and learner (Rahimi et al., 2015; Weller, 2014). The open learner, then, appears as a figure who is in control of his or her own learning process because he or she is involved in choosing (and, if necessary, adapting) the proper software applications needed for his/her learning, and is able to co-determine which content he or she is making use of precisely (Farrow, 2016).

A third conception partly originated from the previous one, and situates open learning within collaborative and distributed activities between learners. This conception is often deployed in order to designate the generation of new modes of learning that are brought about by moving away from individual (student) capital, (top-down) institutional power and reputation, and a one-to-many mode (e.g., teacher-to-learners) of organizing education. Instead, this conception associates open learning with a many-to-many or peer-to-peer mode of organizing educational activities, of which extensive decentralization, networked social relations, and communal knowledge generation are central features (Peters, 2014). Consequently, traditional notions as "curriculum," "teaching," and "pedagogy" are expected to move away from a hierarchical, top-down model, and should instead be mutually and socially constructed (Cormier, 2008). This third conception has been particularly deployed within cMOOCs, which attempt to install and cultivate learning through the mutual construction and exchange of knowledge. In doing so, participants (teachers and students the like) are considered as equal learners within, and contributors to, the network of knowledge formed in and through the course (Downes, 2008; Siemens, 2005). Hence, this third conception considers open learning as collaborative and communal peer learning, that is, as a distributed practice among individuals who uphold an equal social status-thereby emphasizing that such learning is established in and through peer feedback, networking, sharing and connectedness (Siemens, 2005; Brown and Adler, 2008).

Lastly, a fourth way of thinking is more exclusively situated at the level of the open learner (but as a consequence of his or her open learning). The open learner, by being able to learn freely, in control of the software and contents he or she is using, and making use of all the affordances that his/her community of peers affords, is often assumed to be able to break away from his or her own societal position as well as from established educational structures. By and through open learning, it is stated, students could be emancipated from institutional control (stipulating, for instance, what and how to learn) as well as from prevailing societal and economical models (such as a focus on human capital and the commodification of academic labor and education) (Oliver, 2015). Hence, this fourth conception frames the open learner as an individual capable of freeing him/herself-alone or in collaboration with others - from dominant, capitalist modes of wealth and/or elitist education structures. In this regard, this conception is more reductive than the first one, and situates open learning within a freedom of the people undertaking this learning, rather than (only) within free resources (e.g., Winn, 2015). Even though this conception has been criticized for making unsubstantialized claims on this behalf, a theoretical orientation toward individual emancipation clearly constitutes a key point in thinking about the nature and finality of open learning and the open learner (Knox, 2013).

In sum, these four ways of thinking about open learning and the open learner characterize some of the key aspects of the ideological milieu out of which contemporary OE platforms originated. Even though these conceptions are to be placed on a continuum rather than being deterministic dichotomies (for each conception, different degrees of openness exist), interconnected (ideas about open learning often concur and are not easily dissociated from each other), and comprehensive (together, they 
convey a complex sense of the kind of learning to be effectuated by the open learner), they are not allencompassing: Other associated ways of thinking about open learning can be discerned in the literature (e.g., fluid learning; Muñoz et al., 2013). Nevertheless, taken together, they highlight some of the key ways in which open learning, and the figure of the open learner, are ideally approached.

In the next section of this article, we analyze the dominant sorts of $\mathrm{xMOOC}$ platforms that have concretized out of this milieu, and more particularly the operations that these platforms perform in view of enacting specific sorts of open learners (and ideas about open learning). Three reasons make this an important critical task. First, on a very pragmatic level, these platforms are (considered to be) critically part of the contemporary OE landscape, for instance in academic literature, European education policies, and popular discussions (Decuypere, 2016; Dumitrica, 2017). Second, an analysis of the theoretical ideas circulating around open learning as discussed in this section is not only crucial in order to apprehend the conceptual milieu out of which these platforms have concretized, but equally in order to be able to critically describe these operations in view of these ideas. Put otherwise: the specific operations that concrete platforms perform, and the specific kind of learner/learning that these operations enact, can be considered to be a further socio-technical concretization of their surrounding conceptual milieu (Peters and Britez, 2008; Simondon, 1980). Third, and most importantly, these descriptions allow one to understand how agency is relationally distributed within contemporary OE platforms: Not only are the specific sorts of learners (and learning) that are called to exist an effect of these operations, these platforms are equally partly creating new circulating ideas that might, in their turn, be considered as a further concretization of the conceptual milieu around open learning (Emejulu and McGregor, 2016). To that effect, each set of operations will be discussed in contradistinction with the four general ideas above.

\section{Luring and flexibilizing the open learner}

As a starting observation, it can be noted that many of the dominant xMOOC platforms are not explicitly presenting themselves as "open" platforms. Instead, they are quite reserved in adopting "open" terminology. For instance, on the about pages of their respective websites, edX mentions "openness" only in relation to its platform being open source; Coursera and FutureLearn in relation to universal accessibility (open to anyone); and Udacity doesn't mention it at all. Despite their contemporary popular association with openness (especially in media and in education policiesDumitrica, 2017), many platforms are thus not particularly inclined to understand themselves explicitly in these terms.

However, as far as the first conception of openness, which associates open learning with free learning, is concerned, all platforms do partly relate to the idea of providing education free of charge. For instance, edX's website identifier states "free online courses from the world's best universities" and additionally emphasizes this freeness by putting it on the very top of its website (see Figure 1a). Furthermore, edX conceives of its mission as "increasing global access to quality education" (edx.org). Udacity (2018) adopts a vaguer parlance, which still emphasizes accessibility and democratizing potential, yet without explicitly mentioning being free of cost: "Our mission is to democratize education through the offering of world-class higher education opportunities that are accessible, flexible, and economical." Likewise, FutureLearn (2018) states that nearly every course on the platform can be accessed freely, yet only for a limited period of time, with reduced access to contents and tests, and without accompanying certificates (see Figure 1b). Courses are furthermore "accessible on mobile, tablet and desktop, so you can fit learning around your life." Lastly, and similar to FutureLearn, the Coursera platform allows users to explore lectures and non-graded material for free, and stresses at 
the same time that learning can take place irrespective of time and place by providing a platform "where anyone, anywhere can learn and earn credentials from the world's top universities and education providers" (Coursera, 2017). Thus, while "learning" is presented as being free, "earning" (through assessment and/or certification) needs to be paid for.
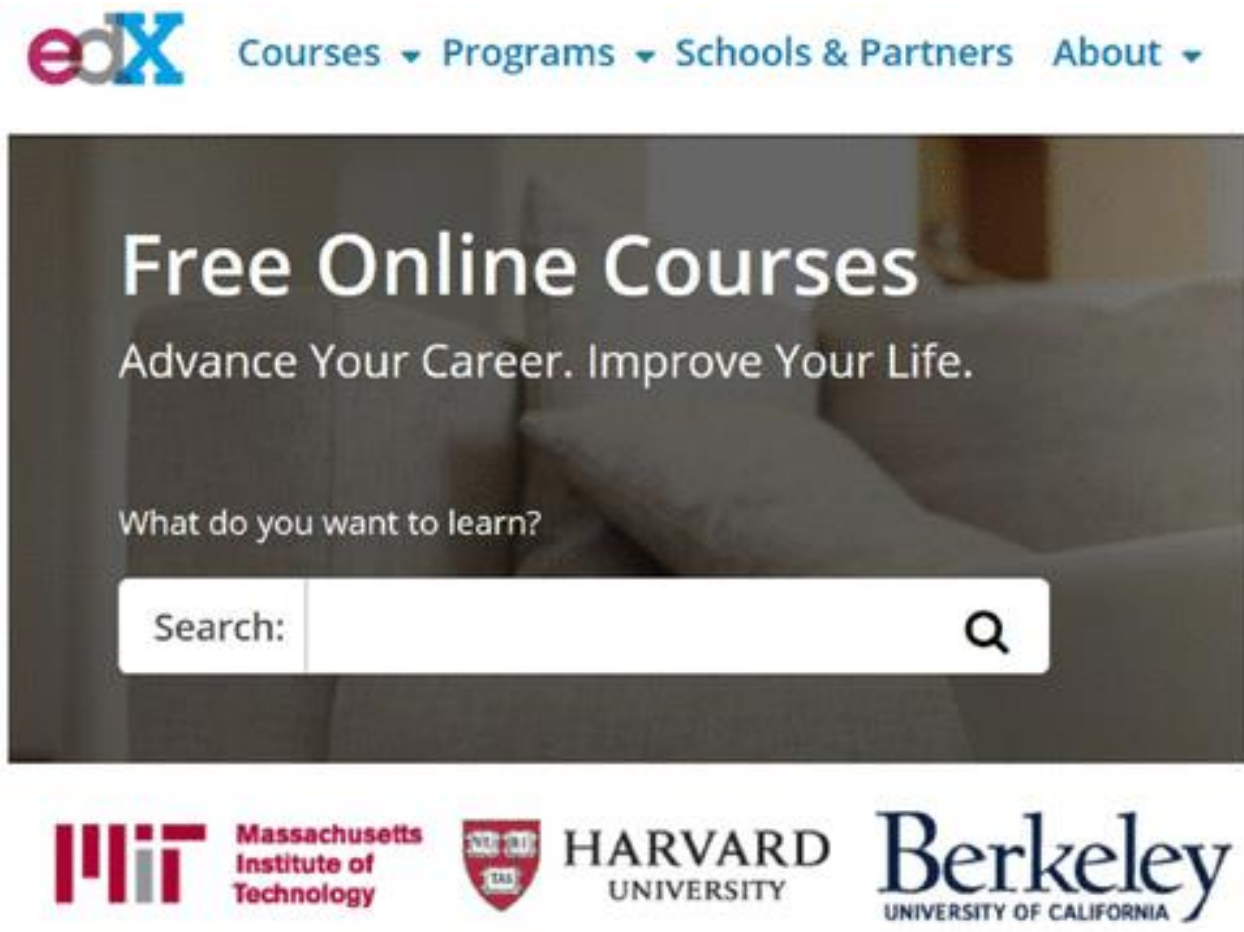

AN INTRODUCTION TO JAPANESE SUBCULTURES KEIO UNIVERSITY

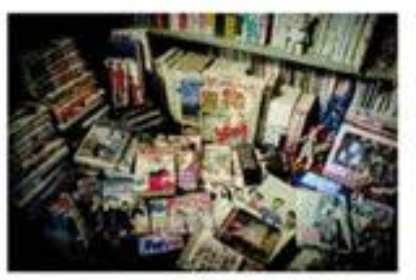

Your access to this course has expired. To get unlimited access and restore your progress upgrade for $€ 54$.

Course info - Leave this course

\section{Why upgrade? Upgrade}

Figure 1. Luring the open learner by stressing freeness (top; edX) and by inviting the user to upgrade through payment (bottom; FutureLearn).

From the above, it is clear that "free" has taken up a very specific meaning that doesn't entirely coincide with free usage. All platforms adopt a business model that operates under a freemium logic: Even though access to the contents of platforms is most of the time free of charge, important other features (that give credibility to the learning of the open learner), such as proctored examination, accreditation and certification, are to be paid for. Hence, for the open learner, the manifest cost of education is shifting from traditional entrance fee to exit fee in order to demonstrate his or her achieved outcomes and make these outcomes credible: The moment one wants to procure evidence that, and what, one has learned, open learners are increasingly expected to purchase a badge, certificate or diploma.

Thus, offering free contents constitutes one way of luring the open learner onto dedicated platforms. Yet, such luring is not only being done by offering freely consumable materials. The open learner is equally being convinced by invoking institutional affiliations, as illustrated in Figure 1a. By presenting 
institutional (often Ivy League) involvement likewise, platforms not only give these educational institutions a central and authoritative position, they equally convey the message that they themselves are merely carriers/providers of content that is delivered by trustworthy institutions. Furthermore, the open learner is not only lured by showcasing educational authorities: Equally non-educational organizations such as famous (Silicon Valley) corporations and non-governmental organizations (e.g., UNESCO) are being given central, authoritative positions (see Figure 2).
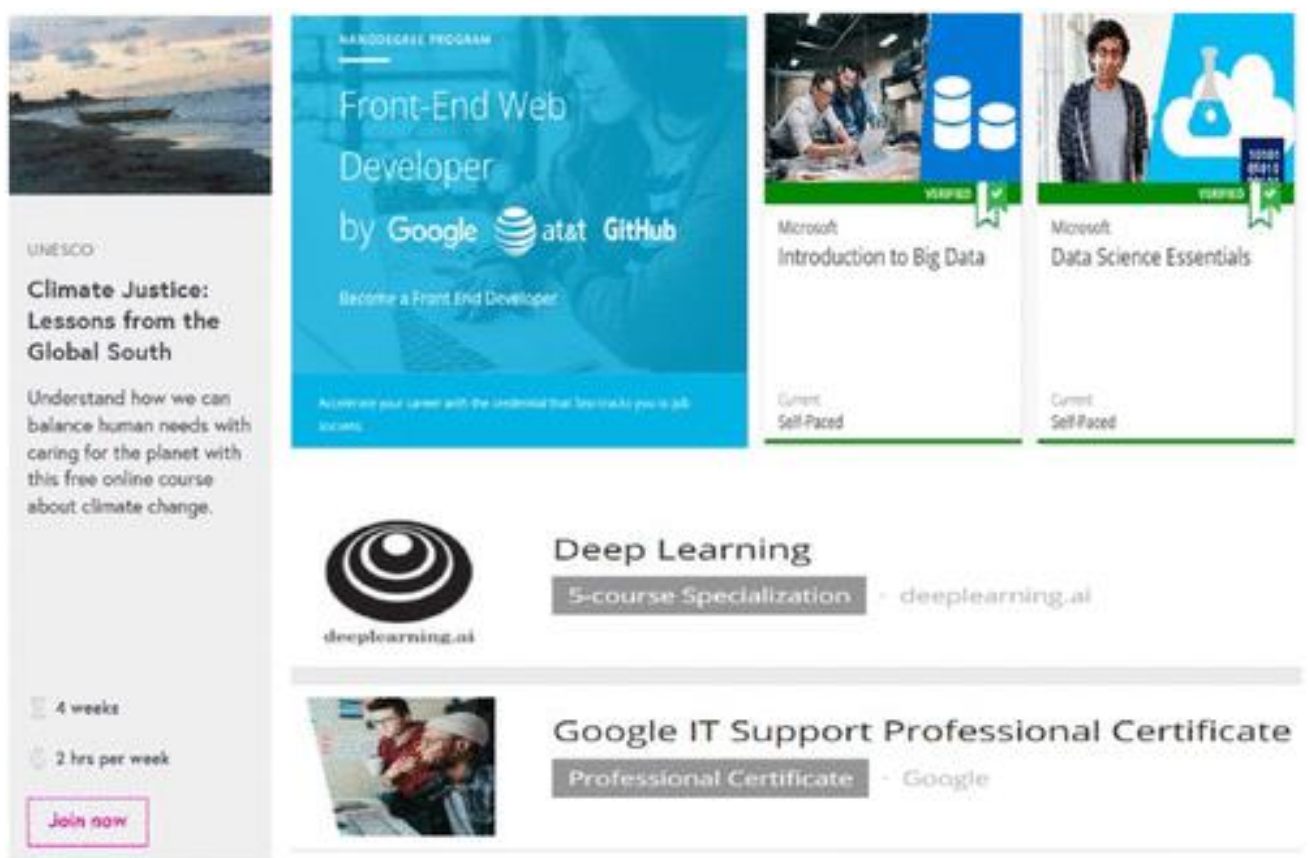

Deep Learning

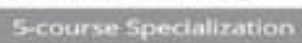

Google IT Support Professional Certificate Professional Certificate

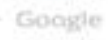

Figure 2. Authorization through institutional affiliation (from left to bottom right: FutureLearn, Udacity, Coursera, edX).

By luring open learners to enter courses that are partly free of charge and delivered by knowledgeable and trustworthy organizations, $\mathrm{xMOOC}$ platforms operate as persuasive technologies. By presenting themselves as being nothing more than mere content providers, these platforms are rendered trustworthy precisely because they displace trustworthiness to other (allegedly more knowledgeable) organizations. Platforms' authority, hence, is being obtained by "outsourcing" it to someplace else (cf. Latour, 1987).

One more way of luring the open learner is established by enticing him or her to continuously (re)visit platforms. Operating as motivating devices, this is brought about by e-mail reminders which, once the user is registered, enter the open learners' mailboxes on a very regular basis and which seek to persuade the open learner to start (or continue) learning as soon as possible. Platforms seek to recruit open learners by addressing them personally and commanding them to "start today" when not yet enrolled in a course or to "keep the momentum" once registered. Equally, e-mail messages stress that learning is a feat to be attained by the open learner him/herself: "You could buy a premium coffee every day for a month. Or, you can invest in yourself and your career with a verified certificate" (all personally addressed e-mail communications to registered users).

In sum, the open learner is shaped as a figure that needs to be lured and convinced to start or continue learning. Additionally, all platforms seek to convince the open learner to enter their courses by heavily 
stressing the potential ubiquitous nature of, and hence considerable flexibility in, the learning happening on these platforms-anywhere, anytime, through any device, etc. (Knox, 2016). In that sense, platforms shape the open learner as someone devoid of contextual characteristics and endowed with a significant amount of flexibility: The open learner is assumed to possess the flexible capacity to learn irrespective of where he or she is positioned in time and space. The corollary of this flexibility offered to, and expected on behalf of, open learners is that platforms equally operate in a manner that is as contextless as possible: In order to operate anywhere, anytime and on any device, platforms are characterized by accessibility through being completely devoid of contextual characteristics. At the same time that platforms are being stripped of contextual characteristics, courses themselves are imbued with contextuality: They are offered by specific organizations and/or institutions that all have a physical counterpart residing in a particular context (often manifestly visualized by embedded pictures showing physical brick and mortar institutions; Knox, 2016).

\section{Controlling and molding the open learner}

By being rendered increasingly flexible, the open learner is equally assumed to be increasingly in control of his or her own learning. In order to apprehend the amount of control the learner has over the platforms he or she is navigating, and over the contents he or she is making use of, a proper place to start is the relation between platforms and the licensing models they adopt. As far as what the open learner is allowed to do on these platforms is concerned, ideas about "mixing and mashing" are at present seldom explicitly mentioned, with the exception of edX. EdX has made the code of its platform public under the name of Open edX. Basically, edX provides the tools that allow the user to develop a course management system based on the source code of its own platform (edX, 2016a). The code on which this platform is built hence correlates with the FLOSS principle that stipulates a maximum amount of user control. This is notably different from most platforms, which are strictly licensed and do not provide the option to adopt-let alone to tweak and adapt-the code on which their platforms are based. Yet, learner control extends much further than the strict and rather one-sided view of (user) control of source code. With respect to control of the course contents, the situation is much more similar for all of these four platforms: Contents (i.e., learning materials and the aggregation of learning materials into courses) are all proprietary and strictly licensed, unless where noted otherwise and under the discretion of individual course providers. edX is the only platform whose terms of service strive for greater future openness: All content is (currently) under copyright control, even though "we aim to make much of the edX course content available under more open license terms" (edX, 2014). Consequently, the open learner appears as a figure whose projected activities are largely delineated to the consumption, rather than the production (e.g., through mixing and mashing), of the course content.

This strict technical consideration of how the open learner can and should deal with course materials and platform code constitutes only a very limited part of what there is to say about coding, since these technicalities themselves say nothing about how such coding shapes particular types of open learners. When considering coding as a performative rather than only as a technical given, conversely, the focus shifts from how code actively determines what the open learner is allowed to do (or shielded away from doing), to how it (in the process) operates in shaping particular sorts of open learners themselves (Kitchin, 2015). For instance, code actively shapes the amount of control the open learner has over his or her own learning trajectory. Platforms are enormously permissive in who is allowed to register for a particular course: Most of the time, no or only a very limited amount of prior knowledge is required to enroll. In that sense, and fully in accordance with platforms' flexibilizing models as outlined above, the open learner is a figure who is allowed to plan his or her own individual learning trajectory and 
who is thence able to progress according to due course. Drawing on this argument, it could even be stated that the open learner is thus a figure who is capable of, and responsible for, mixing and mashing the progression between various courses: He or she is deemed to be able to estimate their own proficiency needed to progress, as well as the courses that could subsequently be taken. Put otherwise, the figure of the open learner is a figure capable of, and responsible for, mapping out his/her own learning trajectory according to his/her own proficiency, needs, and envisaged opportunities (Simons, 2018). At the same time, however, such personal responsibilities are curated by platforms' algorithms, which probe the open learner's interests from the outset, and this in order to offer a personal selection of courses tailored to these interests. Figure 3 offers an example of Coursera, where, after registering and selecting a couple of areas of interest, algorithms actively scan for courses relevant for the personal open learner.

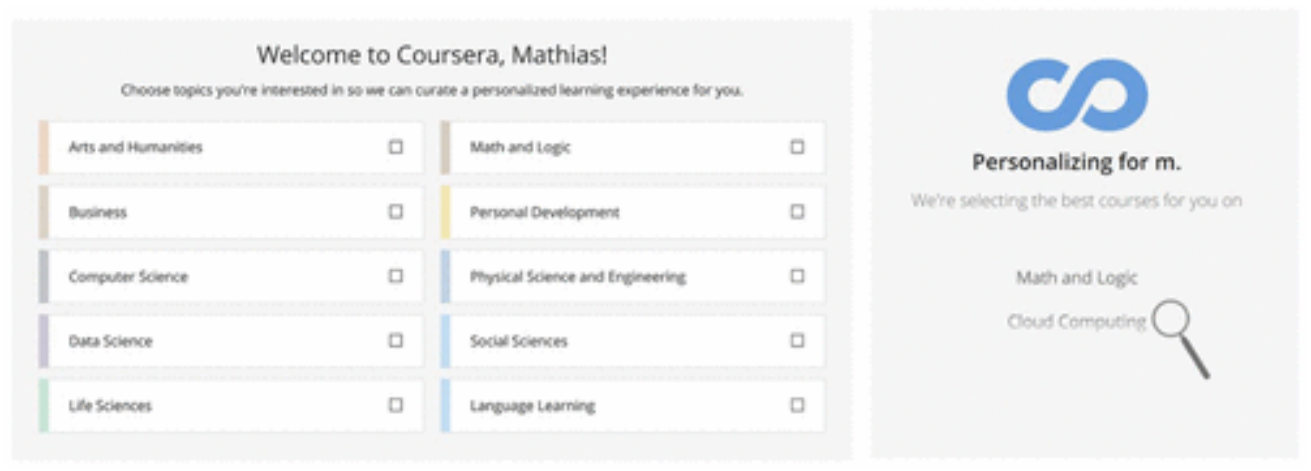

Figure 3. Personalizing the open learner through algorithms and based on individual preferences.

Thus, when registering on platforms, platforms' codes and algorithms shape the open learner as an individual person who is in need of tailored personal learning, and who can-based on this algorithmic personalization-curate his or her own learning trajectory in the variety of courses offered. Yet, this freedom between courses stands in sharp contrast with the open learner's agency within courses. It is particularly at this point that a lens of learner control falls short of being able to capture the way in which the learner is being controlled him/herself by the platforms he or she is visiting.

First, and as discussed already extensively in the literature, platforms control the user in the very selection of subjects they provide: Even though platforms offer tailored personalization algorithms, the open learner is always receiving a selection based on a (biased) catalogue of possible subjects he or she might learn about. For instance, after a contested turn away from the "traditional" educational field, Udacity's course subjects are at present all vocationally oriented (Schuman, 2013), whereas Coursera's course catalogue equally shows an inclination toward disciplines as "business, computer science, data science, and more" (see equally Figure 3). Hence, platforms do not tend to offer a comprehensive range of subjects, but are generally clearly biased toward certain topics and choices (Coursera 2016; Knox, 2017). Consequently, the open learner is controlled in the subjects he or she can study: his/her possible interests are generally confined and largely directed toward vocational subjects that could enable to further his/her career.

Next to this organizational bias toward specific course subjects, a second set of operations that seek to control the learner deals with the control of the open learner once he or she has committed him/herself to entering a particular course. Over the last years, platforms' adoption of learning analytics has exponentially increased. Learning analytics could be defined as "the use of data and models to predict student progress and performance, and the ability to act on that information" 
(Siemens, 2010). Such practices are present in many educational sectors, but are especially topical for OE platforms, which actively seek to log and analyze everything-clicking, keystrokes, viewing times, messages, answers on quizzes, etc. - that a user does online (Van Dijck and Poell, 2015). Taking edX as the example again, the organization has committed itself to research "pedagogy" or "learning about learning" through monitoring the activities of the open learner, and this to the extent that experimentation with the open learner is actively encouraged: "The online environment provides a powerful platform to conduct experiments, exploring how students learn and how faculty can best teach using a variety of novel tools and techniques" (edX, 2016b). The open learner only receives glimpses of this monitoring, for instance by a continuous updating and visualizing of his or her progress in a particular course. As such, the open learner's activities are constantly being positioned in the projected and standardized progress of the course (Figure 4a). By means of such positioning, platforms operate as tracking devices that seek to assist the open learner in progressing according to due course. Whereas Figure 4a doesn't overtly direct the open learner toward a particular course of action, platforms often explicitly direct and steer the activities of its open learners. Figure $4 \mathrm{~b}$ displays how tracked data assist in steering the learning activities of open learners, enticing them to take particular actions and learn in a highly predetermined manner.

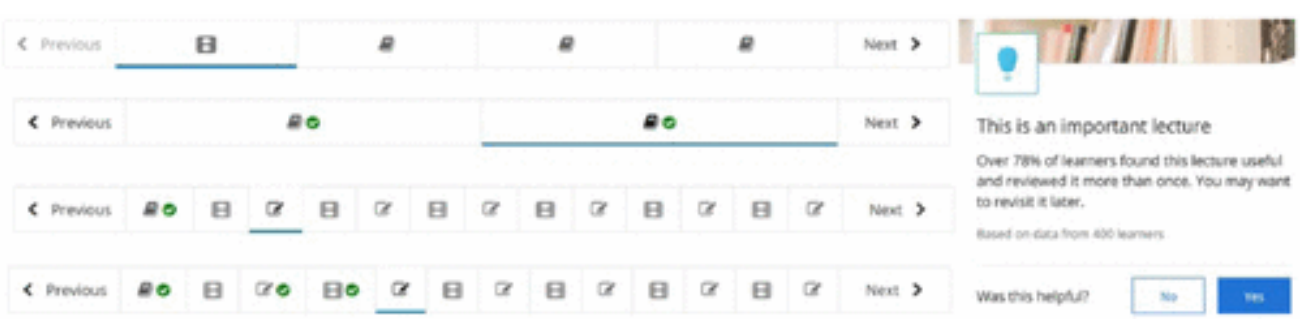

Figure 4. (A) Visualizing the progress of the open learner (edX). (B) Steering the open learner (FutureLearn).

More generally, as far as control is concerned, platforms' monitoring of the activities of the open learner has become of paramount importance in at least two additional respects. First, the logging, tracking, mining, and experimenting with learners' activities and event data in real time is motivated in view of the hope that subsequent statistical analyses might reveal crucial (hidden) aspects of the learning process (e.g., Mukala et al., 2015). In this respect, this dataveillance-the often unmentioned and seemingly non-intrusive practice of monitoring the digital activities of the open learner-is often unwittingly performed (Selwyn, 2015). Furthermore, the possibility of opting out of the collection of personal data is mostly not provided (Prinsloo and Slade, 2015). Second, this monitoring equally sustains the business models of these platforms. As Sal Khan, founder of KhanAcademy-another major platform in the OE field-once stated (in Simon, 2014) about the platform being free: "data is the real asset." The thus constructed data double (Simon, 2005) of the monitored open learner hence operates on a double level: It increasingly shapes the open learner as someone who can be monitored and who can be experimented upon, but it equally increasingly tends to define what open learning is or might be. As much as there is to say about this increasing dataveillance, at the very least it points to a lack of control of the open learner, and more particularly, to an explicit way of providing and guiding his or her learning activities: Open learning amounts to learning what can be measured and what is producing added value, and is hence always necessarily output-oriented (Decuypere et al., 2011; Fenwick and Edwards, 2016). 
Through these various operations of control by, and of, the open learner, the open learner appears as a singularized "prosumer" who is able to consume and eventually complete courses, but who at the same time unwittingly produces all kinds of data that platforms can make use of themselves (for the notion of prosumer, see Williamson, 2016a). With "singularizing," we denote an enhanced form of personalization that not only addresses individuals' learning needs (self-identified and/or captured through data surveillance), but that equally makes each individual conspicuous, that is, at once distinguishable and analyzable (and subject to experimentation). Even though not the explicit focus of this analysis, it could equally be surmised that such singularizing significantly alters what it is to be a teacher: The teacher providing OE is obliged to think about each facet of his/her teaching in terms of measurability and increasing learner performance on indicators determined in advance (cf. Dron and Anderson, 2016).

In sum, the figure of the open learner is a figure who is (partly) in control of what he or she consumes, and hence equally in control of his or her own learning trajectory. Yet, the operations of OE platforms make the open learner at once heavily embedded within a controlling environment him/herself, by heavily steering the sorts of subjects that can be learned about as well as by strictly delineating what counts as open learning. Put otherwise, the open learner is a figure who is stringently molded: not only is he or she incited to navigate his/her learning trajectory within a predefined and licensed field of content that can be consumed but largely not be reconfigured, his/her possible future actions are equally modeled, shaped, and controlled by parameters and observatory mechanisms of which he or she is most of the time not even aware.

\section{Communalizing and responsibilizing the open learner}

The flexible yet molded open learner is often not alone and learns through enjoying him/herself. That is to say, first of all, the open learner is embedded within a community of other group members, who are assisting him or her in learning something. Operating as contextless places, platforms nevertheless regularly seek to actively create a sense of community, for instance by offering dedicated Facebook groups or by integrating community features within the platform itself. Hence, the open learner is offered embedded design features that, even though lacking context, seek to enact communal spaces.

The global community of open learners presented in Figure 5a creates a space in which the open learner is given the message that he or she shouldn't ever feel alone: He or she is always embedded within a (global) community of fellow students that-and this is the crucial point-might be of assistance in enhancing his/her own open learning. Even with respect to these communal features, the establishment of communities of learners is at once complemented with a very strong focus on the individual learner, who can often check his or her progress any time by means of dedicated dashboards and trackers that visualize how one is performing as compared to other community members and what one has (not yet) learned (as can for instance be seen in the progress visualized on the top of Figure $5 b$, or the group referencing in Figure $4 b)$. Communal design features, hence, are explicitly directed at the advancement of individual learning. Put otherwise, even though the open learner might be embedded into communities and might be urged to adopt a collaborative stance toward this community he or she is part of, the finality of collaboration is largely directed at the multiplication of points of view from which feedback might be given, thus aiming to advance the learning of the individual open learner. As such, rather than forging collectivities that shape the contents of learning (as is being done in $\mathrm{cMOOCs}$ ), the central operation performed by installing communities of open learners is a continued and progressive singularizing of the learning experience, and hence, an ideological privileging of individualism above collective values (Watters, 2017). Having the possibility 
to share insights or discuss course topics with other open learners shapes the open learner as someone who has similar interests as his/her fellow learners, and who might benefit from their insights or feedback, as Figure $5 \mathrm{~b}$ shows very clearly. Operations of personalization and singularization (and concomitant pedagogies) are hence combined with communal design features that further reinforce these operations: Groups of singularized open learners are constructed in order to further enhance the open learner's own learning.

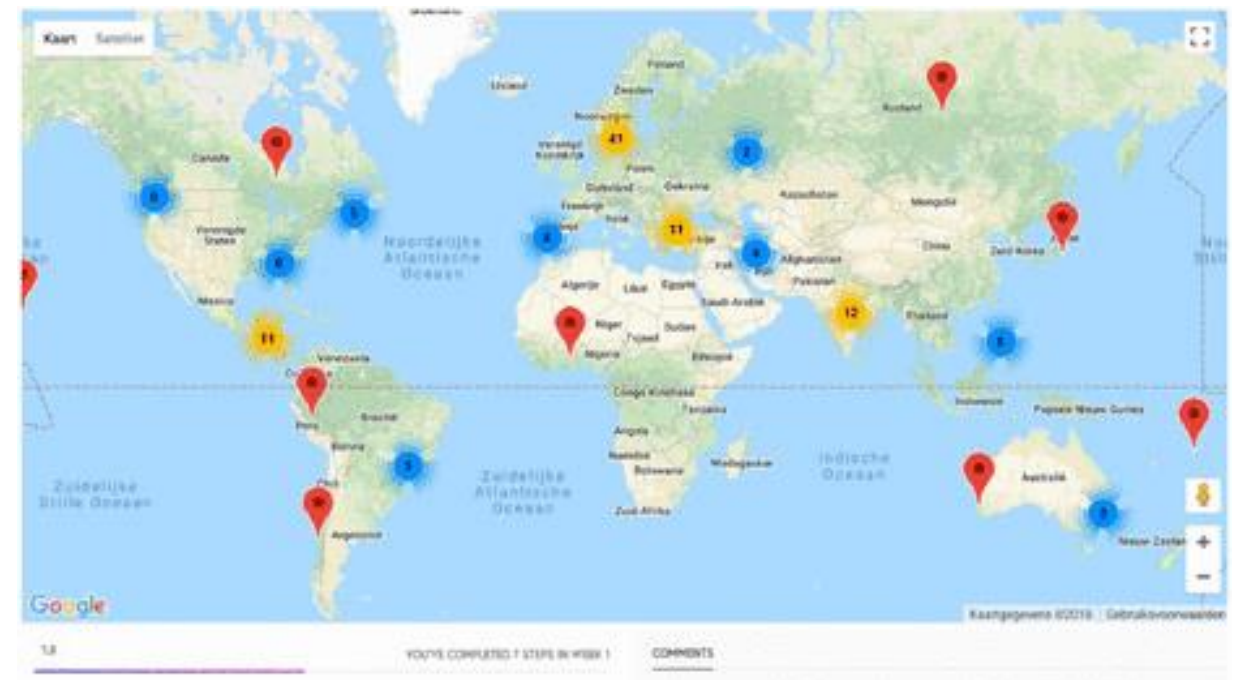

\section{What kind of data would improve effectiveness?}

In this wetivity, wo will consider bow the use of datn from learners cen helb wa to devign offestive blended learning. With oeline learning there are many opportinities to collect data, tert ne need to know what dats to collect, whet implications there are for collecting dat. and how to interperet and use the data mo can accoss.

The following types of digral dato wee esaful for lewring about the extent fo which lesnecs we progrossing towards the intended learning cutcomes:

- Resding comentents in a forum

- Tracking leamers ve activity

- Revils from woomerod tests

- Using voting tools in reiponse to your questions in clens

You will thave become aware of other digtal data as well. Every time o. leaner interacts with a digtal syetem as part of theit study thare in an ocacrturity for digitel dats to be inorded There is therefore the

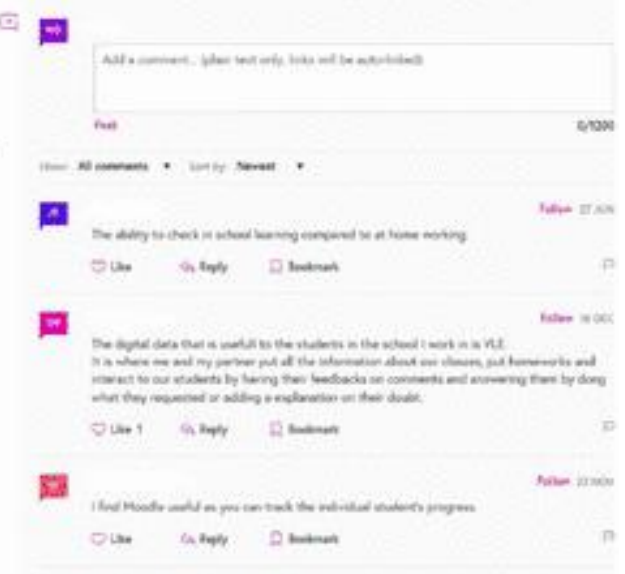

Figure 5. Communalizing the open learner through geographical positioning (top, edX) and through peer discussion (bottom, FutureLearn).

Furthermore, and second, platforms frame this combination of personalization and communalization as inherently fun and enjoyable: The incorporation of communal design features into platforms' code assists the open learner in ascertaining that his/her learning is not only effective and output-oriented, but that the process to get there is being made as attractive and playful as possible. FutureLearn, for instance, conceives of learning as an inherently social activity that is both "enjoyable" (FutureLearn, 2017) and "as easy and natural as chatting with a group of friends" (FutureLearn, 2016b). Udacity equally stresses that learning is "fun" and "really easy" (Watkins, 2015). Current evolutions that "gamify" the learning experience (e.g., earning experience points, unlocking avatars), attempt to make learning as enjoyable as possible, and adapt learning materials based on learners' past performances, further reinforce operations of singularizing (without necessarily taking learners' own contextual characteristics into account; Gourlay, 2015; Williamson, 2017). 
This dovetailing of singularization and communalization adds an additional dimension to the figure of the open learner. The open learner is shaped as a singular person who navigates in a community of like-minded peers, who can offer tailored and direct feedback when needed. With this additional reservoir of social resources at one's disposal, however, the open learner has no longer any excuse for not learning. Especially when learning is assumed to be effortless and associated with ease and enjoyability, it is very clear who is to blame when, eventually, learning did not come about. Thus, the inclusion of communal features and emphases on the play-like and enjoyable nature of open learning causes the locus of responsibility for what is being learned to fall exclusively on the shoulders of the open learner, who therefore nevertheless needs to be endowed with qualities as self-directedness, autonomy, and time-management skills (Morrison, 2012; Simons, 2018). Such responsibilizing leads, furthermore, to assumptions that each user is an entrepreneur of his or her individual learning trajectory, responsible for this trajectory, and in need of the (prosumerist) consumption of content offered. Accordingly, operations of responsibilization entail a profound micro-managing of the learning process from the point of view of the open learner.

\section{Training and empowering the open learner}

Lastly, the open learner is a person who learns. He or she is neither assumed to study, nor conceived as a student. The "learnification" of OE (a term coined by Biesta, 2010 pointing to the observation that education is increasingly and exclusively being thought of in terms of, and reduced to, learning), which responsibilizes individual users to manage their (own) learning, is often proclaimed to empower the open learner. This is made very manifest in the (sorts of) e-mails that subscribers to these platforms receive on a regular basis.

Whereas such e-mail communications seek to "lure" the open learner (see above), they equally address the open learner in a very specific way, by urging her to "gain the skills employers are looking for"; "get learning and get hired"; "get started in this CEO training camp"; etc. (Figure 6). Thus, platforms not only offer a strong biased selection in favor of vocationally oriented topics, thereby controlling which things the open learner might learn precisely; they equally address the open learner as someone who needs to be empowered (cf. Peters and Britez, 2008). Empowerment, however, is taking on a very specific meaning here-namely that of strengthening one's position in the labor market by extending one's competences with popular skills and expertise. As such, many platforms are in effect operating in view of the training of singular prosumers in order to allegedly increase their employability (as the increasing focus on corporate and/or labor training equally attests). However, it can be questioned whether foci on personal empowerment and training contribute to individual emancipation, as was originally stipulated when thinking about open learning (see above). Especially in the case of strong objectivist approaches to learning deployed by xMOOCs, the learning model adopted implies the assumption that everyone learns in identical ways. This has led to the supposition of a generic type of open learner and, consequently, to course curricula that are largely universal and assumed to work for everybody (Gourlay, 2015; Hall, 2015). It goes without saying that such assumptions about universality have precisely led to exclusions of those who do not feel addressed by the generic image of the open learner: By and large, the open learner tends to be male, graduated, and prosperous (Farrow, 2016). The significant prevalence of such exclusions implies that present OE platforms tend to invigorate the competences and societal position of individuals already occupying a privileged position, and hence that their proclaimed emancipatory potential should, at the very least, be put under critical scrutiny (Emejulu and McGregor, 2016). 


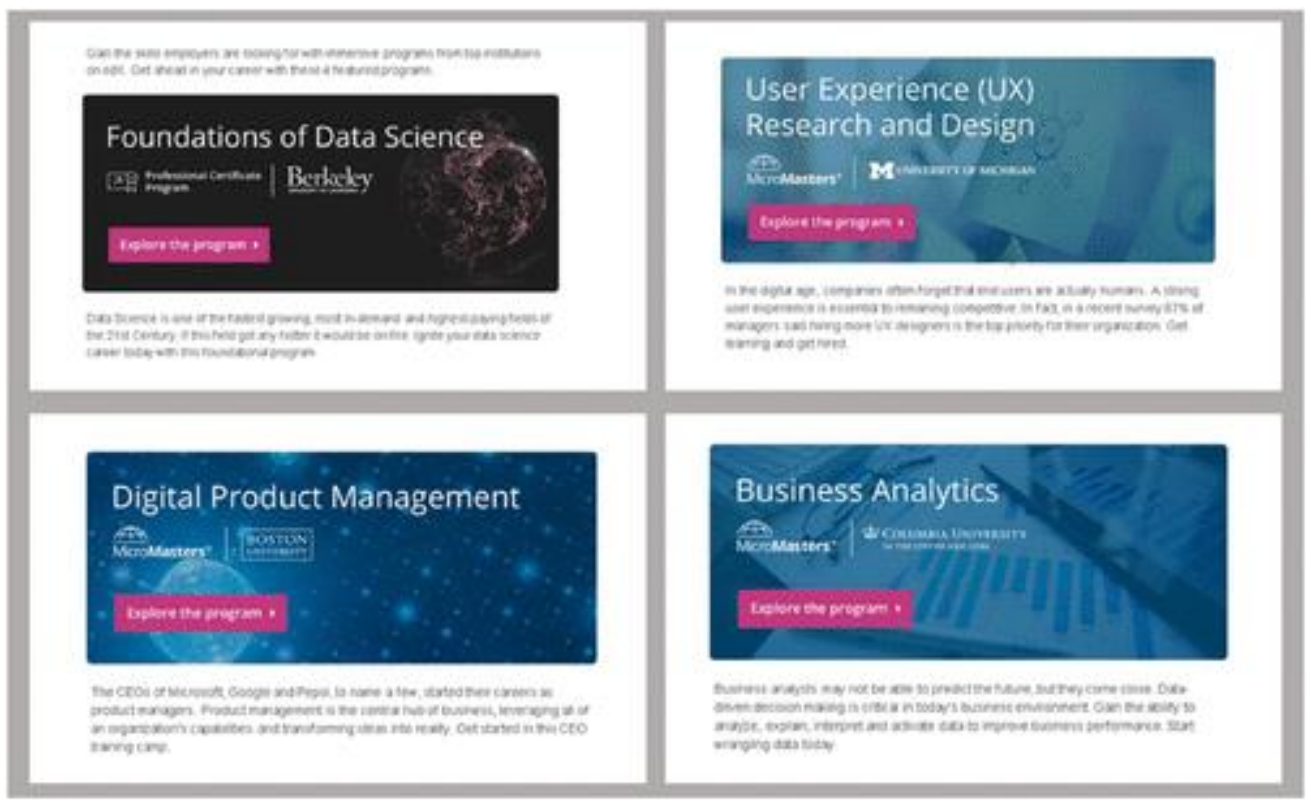

Figure 6. Training and empowering the open learner (parts of an edX e-mail communication).

\section{Some outlines for future concretizations of OE platforms and their milieus}

By focusing on the operations of some of the platforms that are characteristic of OE nowadays, and how they have concretized out of a specific sort of conceptual milieu, this article has offered an account of contemporary $\mathrm{xMOOC}$ platforms as socio-technical devices that act and, by doing so, enact a specific figure of the open learner. By confining ourselves to the platform environments themselves, this analysis is necessarily portraying only a fraction of the different operations at work in the construction and usage of digital open educational platforms. For instance, the figure of the open learner being enacted need not be considered deterministically, and thus will not necessarily manifest itself likewise in and through concrete practice: Research has amply shown how actors interpret, steer and (re-)direct projected enactments in specific ways. This analysis, then, did neither account for such concrete forms of subversive and/or unruly behavior, nor for the lived experiences of learners on these platforms (e.g. Souto-Otero and Beneito-Montagut, 2015). Analogously, by not accounting for the agency of other actors that are equally crucially part of the contemporary OE constellation (for instance of teachers, university administrators, newspaper articles, and policy makers), this article only considered a tiny part of this constellation (Hartong, 2016). However, this analysis of theoretical ideas, digital operations and the figure of the open learner did allow for a concrete showcasing of relational processes currently at work within this constellation. To be clear: This analysis neither aimed to unveil what true or veracious $\mathrm{OE}$ principles consist of, nor to adumbrate how MOOC platforms possibly thwart the further concretization of these principles. Instead, it offers an account of what is at stake at present in MOOC platforms, and how these platforms configure what it is to be an open learner nowadays.

So, what is at stake? The lens of socio-technical devices allowed us to make a double argument. First, despite their undertheorized status, MOOC platforms have proliferated not only in specific contexts, but equally out of specific theoretical ideas. Critical analyses of platforms should not amount to a form of determinism that assumes these platforms to unavoidably be susceptible to corporatizing tendencies that necessarily do away with their surrounding conceptual milieu. On the contrary, this analysis shows that it would be a mistake to straightforwardly assume that these platforms have vitiated all of these ideas. Rather than having completely eclipsed their theoretical basis, MOOC 
platforms are constituted by an increasingly convoluted assemblage of which some of these conceptual ideas about OE constitute one part, sided by corporate interests and neoliberal mentalities, but equally by very specific ideas about what education itself is or should be.

In that respect, and secondly, $\mathrm{MOOC}$ platforms are not only the concretization itself of the relational constellations in which they are situated, but in their turn concretize particular users and types of education. Operating as active devices, they promote specific ideas about what a valuable education should consist of and about the users they envisage to create. As such, these platforms not only stabilize particular desired ways of who its users are and ought to be (i.e., open learners), but equally stabilize particular conceptions of what education is (i.e., productive and measurable learning-astraining). Hence, the shaping of the open learner equally leads to a newly proliferating conceptual milieu that is significantly reshaping our traditional understanding of the role and place of education in society (see e.g., Masschelein and Simons, 2012).

Instead of evaluating or judging these evolutions, we end this article with some closing thoughts about possible future concretizations of $\mathrm{OE}$ (and its platforms). At least three possible evolutions of the future $\mathrm{OE}$ constellation could be envisaged. The first evolution amounts to continuing or strengthening the commonly held theoretical ideas in the contemporary constellation (and hence, aiming to further concretize the conceptual milieu out of which MOOC platforms originated). However, as shown, this option does not seem to constitute a probable concretization of these platforms. A second evolution, therefore, seems far more likely and is situated in a further concretization of the operations described above (Watters, 2016). To the extent that more emphasis will probably be laid on delivering services to the corporate sector (e.g., small rather than massive, private rather than open), it is reasonable to surmise that this pivoting will lead to an intensification of the operations we described above, that is, less user control, more surveillance of user data, more licensing, more molding, in short: An accelerating process of singularizing and learner responsibilization that could eventually lead to completely individualized and tailored courses.

A third evolution would be to explicitly take into account the conceptual milieu identified above, but at the same time be very conscious about the operations that each educational technology unavoidably performs itself (Williamson, 2016b). Explicitly taking into account these theoretical principles would then not imply the unreflexive fetishization of grand ideas, but instead a recognition that in $\mathrm{OE}$, both openness and education are referring to ideas that are worthwhile to explore and concretize into digital design (Peters, 2014). Central questions in this third option would be: How could one attune this conceptual milieu more closely to the affordances of newly emerging educational technologies? How could one generate greater learner control or at least diminish control of the open learner (whatever its concrete form)? How could one avoid a reductionist take on $O E$ that associates xMOOCs only with learning? Answers to such questions would necessarily need to critically adapt or finetune some of these theoretical ideas and principles as well as (and in confrontation with) the practical reconfiguration of the ed-tech toolbox we have presently at our disposal (Selwyn, 2015). Such endeavors are, furthermore, not merely ephemeral theoretical musings, but already proliferating from various angles and in different forms: We only need to look at emerging experimental approaches (such as Commons and arts-based movements, initiatives as learning circles, and so on) to digital education to see the possibilities and fruitfulness of such concretization. Irrespective of the possible routes that $\mathrm{OE}$ and MOOCs might take in the future, it is perhaps our own critical task to keep these options (productively) open.

\section{Declaration of conflicting interest}

The author(s) declared no potential conflicts of interest with respect to the research, authorship, and/or publication of this article. 


\section{Funding}

The author(s) disclosed receipt of the following financial support for the research, authorship, and/or publication of this article: Funding agency: KU Leuven Internal Funds Grant number: C14/18/041.

\section{ORCID iD}

https://orcid.org/0000-0002-0983-738X.

Notes

1.

All Figures were retrieved from $\mathrm{xMOOC}$ platform websites and from personal e-mail communications.

2.

Figures 1-5 were retrieved from edx.org; futurelearn.com; udacity.com and coursera.org.

3.

Figure 6 was retrieved from a personal e-mail sent to edX members.

\section{References}

Baker FWI (2017) An Alternative Approach: Openness in Education Over the Last 100 Years. TechTrends, TechTrends 61(2): 130-140.

Bayne S, Knox J and Ross J (2015) Open education: the need for a critical approach. Woolgar S (ed.), Learning, Media and Technology, New York: Univ Of Minnesota Press 40(3): 247-250.

Biesta G (2010) Good education in an age of measurement: Ethics, politics, Democracy. Boulder, CO: Paradigm Publishers.

Brown JS and Adler RP (2008) Open education, the long tail, and learning 2.0. Educause review 43(1): 16-20.

Brown M (2016) MOOCs as social practice : a kaleidoscope of perspectives. In: De Corte E, Engwall L, and Teichler U (eds), Emerging models of learning and teaching in higher education: From books to MOOCs., London: Portland Press, pp. 31-42.

Callon M and Muniesa F (2005) Economic markets as calculative collective devices. Organization Studies 26(8): 1229-1250.

Collier A and Ross J (2017) For whom, and for what? Not-yetness and thinking beyond open content. Open Praxis 9(1): 7-16. Available from:

https://openpraxis.org/index.php/OpenPraxis/article/view/406.

Comeau JD and Cheng TL (2013) Digital 'tsunami' in higher education: Democratisation Movement towards Open and Free Education. Turkish Online Journal of Distance Education 14(3): 198-224.

Cormier D (2008) Rhizomatic Education: Community as Curriculum. Innovate: Journal of Online Education 4(5): 6. Available from: http://nsuworks.nova.edu/innovate/vol4/iss5/2.

Coursera (2017) About. Available from: https://blog.coursera.org/about/ (accessed 13 December 2017).

Decuypere, M, Simons, M, Masschelein, J (2011) 'Perform, measure accurately, optimise': On the constitution of (evidence-based) education policy. International Studies in Sociology of Education 21(2), 115-135. 
Decuypere, M, Ceulemans, C, Simons, M (2014) Schools in the making: Mapping digital spaces of evidence. Journal of Education Policy 29(5): 617-639.

Decuypere, M (2016) Diagrams of Europeanization: European education governance in the digital age. Journal of Education Policy 31(6): 851-872.

Decuypere, $\mathrm{M}$ and Simons, M (2016a) Relational thinking in education: Topology, sociomaterial studies, and figures. Pedagogy, Culture \& Society 24(3): 371-386.

Decuypere $\mathrm{M}$ and Simons M (2016b) Continuing attachments in academic work in neoliberal times: On the academic mode of existence. Critical Studies in Education. Available from: https://doi.org/10.1080/17 508487.2016.1240095

Downes S (2008) Places to Go : Connectivism \& Connective Knowledge. Journal of Online Education 5(1): 1-6.

Dron J and Anderson T (2016) The Future of E-learning. 2nd ed. In: Haythornthwaite C, Andrews R, Fransman J, et al. (eds), The SAGE handbook of e-learning research, Sage.

Drucker J (2013) Diagrammatic Writing. new formations: a journal of culture/theory/politics, Lawrence \& Wishart 78(1): 83-101. Available from: https://muse.jhu.edu/journals/new_formations/v078/78.drucker.html (accessed 27 November 2015).

Dumitrica D (2017) Fixing higher education through technology: Canadian media coverage of massive open online courses. Learning, Media and Technology, Taylor \& Francis: 1-14. Available from: https://www.tandfonline.com/doi/full/10.1080/17439884.2017.1278021.

Edwards R and Fenwick T (2015) Critique and Politics: A sociomaterialist intervention. Educational Philosophy and Theory, Routledge 47(13-14): 1385-1404.

edX (2016a) About Open edX. Available from: https://open.edx.org/about-open-edx (accessed 3 October 2016).

edX (2016b) Research \& Pedagogy. Available from: https://www.edx.org/about/research-pedagogy (accessed 3 October 2016).

EdX (2014) Terms of service. Available from: https://www.edx.org/edx-terms-service (accessed 3 October 2016).

Emejulu A and McGregor C (2016) Towards a radical digital citizenship in digital education. Critical Studies in Education, Routledge 00(00): 1-17. Available from: https://www.tandfonline.com/doi/full/10.1080/17508487.2016.1234494.

Farrow R (2016) Open education and critical pedagogy. Learning, Media and Technology 9884(January): 1-17.

FutureLearn (n.d.) About. Available from: https://www.futurelearn.com/about (accessed 5 October 2016a).

FutureLearn (n.d.) About FutureLearn. Available from: https://www.futurelearn.com/aboutfuturelearn (accessed 13 December 2017b).

FutureLearn (n.d.) What would you like to learn? Available from: https://www.futurelearn.com (accessed 5 October 2016c).

Gonzalez-Flor A (2013) Exploring the downside of open knowledge resources: The case of indigenous knowledge systems and practices in the Philippines. Open Praxis 5(1): 75-80. Available from: http://dx.doi.org/10.5944/openpraxis.5.1.15. 
Gorur R (2013) My School , My Market. Discourse: Studies in the Cultural Politics of Education, Routledge 34(2): 214-230. Available from: http://www.tandfonline.com/doi/abs/10.1080/01596306.2013.770248 (accessed 1 December 2015).

Gourlay L (2015) Open education as a 'heterotopia of desire'. Learning, Media and Technology 40(July): 1-18. Available from: http://www.tandfonline.com/doi/full/10.1080/17439884.2015.1029941.

Hall R (2015) For a political economy of massive open online courses. Learning, Media and Technology 9884(May): 1-22. Available from: http://www.scopus.com/inward/record.url?eid=2-s2.0-84924359095\&partnerlD=tZOtx3y1.

Hartong S (2016) Between assessments, digital technologies and big data: The growing influence of 'hidden' data mediators in education. European Educational Research Journal 15(5): 523-536.

Kitchin R (2015) Foreword: Education in code/space. In: Williamson B (ed.), Coding/learning, Stirling: University of Stirling, pp. 1-3.

Kitchin R and Dodge M (2011) Code/Space: Software and everyday life. Cambridge, MA and London: MIT Press.

Knox J (2013) Five critiques of the open educational resources movement. Teaching in Higher Education 18(8): 821-832. Available from: http://www.tandfonline.com/doi/abs/10.1080/13562517.2013.774354\%5Cnhttp://dx.doi.org/1 $0.1080 / 13562517.2013 .774354$.

Knox J (2016) Posthumanism and the MOOC: opening the subject of digital education. Studies in Philosophy and Education, Springer Netherlands 35(3): 305-320.

Knox J (2017) How goes the revolution? Three themes in the shifting MOOC landscape. In: Ferreira G, Rosado A, and Carvalho J (eds), Educação e Tecnologia: Abordagens Criticas, Universidade Estacio De Sa, pp. 386-408.

Krause SD (2014) After the invasion: What's next for MOOCs? In: Krause SD and Lowe C (eds), Invasion of the MOOCs: The promise and perils of Massive Open Online Courses, Anderson, SC: Parlor Press. Available from: http://www.ccweek.com/news/templates/template.aspx?articleid=3342\&zoneid=7.

Latour B (1986) Visualization and cognition: Thinking with eyes and hands. Knowledge \& Society 6: 140. Available from: http://hci.ucsd.edu/10/readings/Latour(1986).pdf (accessed 27 November 2015).

Latour B (1987) Science in Action: How to Follow Scientists and Engineers Through Society. Available from: https://books.google.com/books?hl=nl\&lr=\&id=sC4bk4DZXTQC\&pgis=1 (accessed 27 November 2015).

Marshall SJ (2018) Shaping the University of the Future: Using technology to catalyse change in university learning and teaching. Singapore: Springer.

Masschelein, J; Simons M (2012) In Defense of The School. Leuven: E-ducation, culture and society publishers.

Moe $R$ (2015) OER as online edutainment resources: a critical look at open content, branded content, and how both affect the OER movement. Learning, Media and Technology 40(3): 350-364. A

Morozov E (2013) To save everything, click here: The folly of technological solutionism. Public Affairs. 
Morrison D (2012) How to Encourage Online Learners to take Responsibility for their Own Learning. Available from: https://onlinelearninginsights.wordpress.com/2012/09/07/how-to-encourageonline-learners-to-take-responsibility-for-their-own-learning/ (accessed 11 December 2017).

Mukala P, Buys J, Leemans M, et al. (2015) Learning Analytics on Coursera Event Data: A Process Mining Approach. Bpm: 18-32. Available from: http://ceur-ws.org/Vol-1527/paper2.pdf.

Muniesa F, Millo Y and Callon M (2007) An introduction to market devices. Sociological Review 55(2): $1-12$.

Muñoz JC, Redecker C, Vuorikari R, et al. (2013) Open Education 2030: planning the future of adult learning in Europe. Open Learning: The Journal of Open, Distance and e-Learning 28(3): 171186. Available from: http://www.tandfonline.com/doi/abs/10.1080/02680513.2013.871199.

Oliver M (2015) From openness to permeability: reframing open education in terms of positive liberty in the enactment of academic practices. Learning, Media and Technology 40(3): 365384.

Peters M a. (2014) Openness and the Intellectual Commons. Open Review of Educational Research 1(1): 1-7. Available from:

http://www.tandfonline.com/doi/abs/10.1080/23265507.2014.984975.

Peters MA and Britez RG (2008) Open Education and Education for Openness. Open education and education for openness, Rotterdam: Sense Publishers.

Peters MA and Roberts P (2012) The virtues of openness. Abingdon \& New York: Routledge.

Postma D (2012) Education as sociomaterial critique. Pedagogy, Culture \& Society 20(1): 137-156. Available from: http://www.tandfonline.com/doi/abs/10.1080/14681366.2012.649419.

Prinsloo P and Slade S (2015) Student privacy self-management. In: Proceedings of the Fifth International Conference on Learning Analytics And Knowledge - LAK'15, pp. 83-92. Available from: http://dl.acm.org/citation.cfm?doid=2723576.2723585.

Rahimi E, Van Den Berg J and Veen W (2015) A learning model for enhancing the student's control in educational process using Web 2.0 personal learning environments. British Journal of Educational Technology 46(4): 780-792.

Rosa R De, Ferrari C and Kerr R (2017) The EMMA experience. Emerging patterns and factors for succes. In: Delgado Kloos C et al (ed.), EMOOCS, pp. 20-28. Available from: http://link.springer.com/10.1007/978-3-319-59044-8.

Schuman R (2013) The King of MOOCs Abdicates the Throne. Slate. Available from: http://www.slate.com/articles/life/education/2013/11/sebastian_thrun_and_udacity_distance _learning_is_unsuccessful_for_most_students.html.

Selwyn N (2015) Data entry: towards the critical study of digital data and education. Learning, Media and Technology, Routledge 40(1): 64-82. Available from: http://www.tandfonline.com/doi/abs/10.1080/17439884.2014.921628 (accessed 31 October 2015).

Serres M (2015) Rome: The first book of foundations. London: Bloomsbury.

Siemens G (2005) Connectivism: A learning theory for the digital age. International Journal of Instructional Technology and Distance Learning 2(1).

Siemens G (2010) What are Learning Analytics? Available from: http://www.elearnspace.org/blog/2010/08/25/what-are-learning-analytics/ (accessed 18 
December 2017).

Simon B (2005) The Return of Panopticism : Supervision, Subjection and the New Surveillance. Surveillance \& Society 3(1): 1-20.

Simon S (2014) The big biz of spying on little kids. Available from: https://www.politico.com/story/2014/05/data-mining-your-children-106676 (accessed 23 July 2016).

Simondon G (1980) On the mode of existence of technical objects. University of Western Ontario.

Simons M (2015) Education policy from the perspective of governmentality. In: Smeyers P, Bridges D, Burbules NC, et al. (eds), International Handbook of Interpretation in Educational Research, Dordrecht, The Netherlands: Springer, pp. 1165-1188.

Simons M (2018) Refiguring the European student: Mixed transnational feelings. In: Hultqvist E, Lindblad S, and Popkewitz T (eds), Critical analyses of educational reforms in an era of transnational governance, Springer, pp. 169-184.

Stallman R (2016) FLOSS and FOSS. Available from: https://www.gnu.org/philosophy/floss-andfoss.en.html (accessed 22 March 2017).

Storme T, Nancy Vansieleghem B, Devleminck S, et al. (2016) The emerging pedagogy of MOOCs, the educational design of technology and practices of study. Journal of Computers in Education, Springer Berlin Heidelberg 3(3): 309-328.

Tuomi I (2013) Open Educational Resources and the Transformation of Education. European Journal of Education 48(1): 58-78.

Udacity (2018) About us. Available from: https://www.udacity.com/us (accessed 23 March 2018).

Van Dijck J and Poell T (2015) Higher Education in a Networked World: European Responses to U.S. MOOCs. International Journal of Communication 9: 19. Available from: http://ijoc.org/index.php/ijoc/article/view/3398.

Watkins C (2015) Seven Beginner's Courses That Everyone Can Master. Available from: https://blog.udacity.com/2015/09/seven-beginners-courses-that-everyone-can-master.html.

Watters A (2016) Education technology and the promise of 'free' and 'open'. Available from: http://hackeducation.com/2016/12/07/top-ed-tech-trends-free-open (accessed 22 September 2017).

Watters A (2017) Education technology as 'the new normal'. Available from: http://hackeducation.com/2017/05/24/new-normal (accessed 25 May 2017).

Weller M (2014) The Battle for open: How openness won and why it doesn't feel like victory.

Weller M, Jordan K, DeVries I, et al. (2018) Mapping the open education landscape: citation network analysis of historical open and distance education research. Open Praxis 10(2): 109-126. Available from: https://openpraxis.org/index.php/OpenPraxis/article/view/822.

Wiley D and Green C (2012) Why openness in education? In: Oblinger DG (ed.), Game Changers: Education and Information Technologies, Educause, pp. 81-89.

Williamson B (2016a) Digital education governance: data visualization, predictive analytics, and 'realtime' policy instruments. Journal of Education Policy, Routledge 31(2): 123-141. Available from: http://dx.doi.org/10.1080/02680939.2015.1035758.

Williamson B (2016b) Silicon startup schools: technocracy, algorithmic imaginaries and venture 
philanthropy in corporate education reform. Critical Studies in Education, Routledge 00(00): 119. Available from: http://dx.doi.org/10.1080/17508487.2016.1186710.

Williamson B (2017) Decoding ClassDojo: psycho-policy, social-emotional learning and persuasive educational technologies. Learning, Media and Technology, Taylor \& Francis 42(4): 440-453. Available from: https://doi.org/10.1080/17439884.2017.1278020.

Winn J (2015) Open education and the emancipation of academic labour. Learning, Media and Technology 40(3): 385-404.

Yuan L and Powell S (2013) MOOCs and Open Education: Implications for Higher Education. Cetis: 19. Available from: http://publications.cetis.ac.uk/wp-content/uploads/2013/03/MOOCs-andOpenEducation.pdf\%5Cnhttp://publications.cetis.ac.uk/2013/667\%5Cnhttp://www.smarthighered.c om/wp-content/uploads/2013/03/MOOCs-and-Open-Education.pdf. 